\title{
Retos y alcances de la vecindad de México con Estados Unidos. Mirada desde el escritor mexicano José Revueltas*
}

\author{
Challenges and scope of the vicinity of Mexico \\ with the United States: A look from the perspective \\ of the Mexican writer José Revueltas \\ Retos e alcances da proximidade de México \\ com os Estados Unidos: Olhada desde \\ o escritor mexicano José Revueltas
}

Recibido el 25 de marzo de 2014, aceptado el 30 de abril de 2014

\author{
Rosa María Valles Ruiz** \\ México
}

\section{Resumen}

Objetivo: analizar el artículo "Los intelectuales mexicanos frente a Norteamérica" y el subtítulo "Con los Estados Unidos de mañana", publicado en 1943 por el mexicano José Revueltas, sobre los retos y alcances de la vecindad de México con Estados Unidos. Con esto

Valles Ruiz, Rosa María (2014). Retos y alcances de la vecindad de México con Estados Unidos. Mirada desde el escritor mexicano José Revueltas. Ánfora,

21(36), 67-90. Universidad

Autónoma de Manizales. ISSN 0121-6538. se explican -en estrecha relación con el contexto de la Segunda Guerra Mundial- las razones geopolíticas e históricas de la relación entre ambas naciones. Metodología: se analizó, semánticamente, el contenido del artículo. El método de análisis del discurso, permitió ampliar y profundizar el significado del artículo. Se siguió

\footnotetext{
* Este artículo se deriva de una investigación que se orienta a la compilación e interpretación de textos denominada José Revueltas. Letras rescatadas, trabajo en proceso de la autora. Proyecto financiado por la Universidad Autónoma del Estado de Hidalgo (México) en el marco del Programa Integral del Fortalecimiento Institucional (PIFI) 2014.

** Profesora-Investigadora de la Universidad Autónoma del Estado de Hidalgo (México). Pertenece al Sistema Nacional de Investigadores. Trabaja las líneas de investigación Análisis del discurso, análisis de los medios de comunicación, Género e Historia, Historia Oral y Memorias Históricas. vallezcurdia@gmail.com
} 
la línea metodológica que subraya que las expresiones discursivas no se separan de la situación en que han sido emitidas. Cada evento comunicativo cumple la función de expresar algún pensamiento o sentimiento efectivo en ese momento y en esa situación.

Resultados: la mirada del escritor José Revueltas sobre las relaciones México-Estados Unidos, en el contexto de la Segunda Guerra Mundial, se caracteriza por destacar los elementos civilizatorios que hacen ver la posibilidad de establecer una convivencia pacífica y respetuosa en ambos países. Se evidencia la habilidad del escritor para usar la polifonía y algunas categorías del análisis estilístico. El análisis refleja las aristas conflictivas de las relaciones entre México y Estados Unidos. Conclusiones: el contexto de la Segunda Guerra Mundial influye en el escritor, porque su discurso se encuentra inmerso en una situación social en la cual México forma parte de los Aliados, junto a Estados unidos, en la contienda internacional.

Palabras clave: Análisis del discurso, Relación México-Estados Unidos, Polifonía, Análisis estilístico

\begin{abstract}
Objective: toanalyzethearticle"MexicanintellectualsagainstAmerica" and thesubtitle "With tomorrow's United States" published in 1943 by the Mexican José Revueltas, on the challenges and scope of the vicinity of Mexico with the United States. Thus, in close relation to the context of the Second World War, the geopolitical and historical reasons of the relationship between the two nations are explained. Methodology: the contents of the article were semantically analyzed. The method of discourse analysis permitted expansion and deeper analysis into the meaning of the article. The methodological approach adopted emphasizes that the discursive expressions are not separated from the situation in which they were issued. Each communicative event serves to express some effective thinking or feeling at that time and in that situation. Results: the perspective of the writer José Revueltas on the Mexico-USA relationship in the context of World War II is characterized by noting the civilizing elements that make evident the possibility of a peaceful and respectful coexistence in both countries. The writer's ability to use polyphony and some categories of stylistic analysis are evident. The analysis reflects the conflicting edges of relations between Mexico and the United States. Conclusions: the context of World War II influences the writer, because his speech is immersed in a social situation in which Mexico is part of the Allies, with the USA in the international contest.
\end{abstract}

Keywords: Discourse Analysis, Mexico-US Relationship, Polyphony, Stylistic Analysis 


\section{Resumo}

Objetivo: analisar o artigo "Os intelectuais mexicanos frente a Norte América" e o subtítulo "Com os Estados Unidos de manha", publicado e 1943 pelo mexicano José Revueltas, sobre os retos e alcances da proximidade de México com Estados Unidos. Com isto se explica - em estreita relação com o contexto da Segunda Guerra Mundialas razoes geo - políticas e históricas da relação entre os dois países. Metodologia: se analisou, semanticamente, o conteúdo do artigo. O método de análises do discurso permitiu ampliar e aprofundar o significado do artigo. Seguiu-se a línea metodológica que sublinhar que as expressões discursivas não se separam da situação em que tem sido emitida. Cada evento comunicativo faz a função de expressar algum pensamento ou sentimento efetivo nesse momento e nessa situação. Resultados: uma visão do escritor José Revueltas sobre as relações México - Estados Unidos, no contexto da Segunda Guerra Mundial, caracteriza se por destacar os elementos civilizatórios que fazem ver a possibilidade de estabelecer uma convivência pacifica e respeitosa nos dois países. Evidencia se a habilidade do escritor para usar a polifonia e algumas categorias do analise estilístico. $\bigcirc$ analise reflete as aristas o conflito das relações entre México e Estados Unidos. Conclusões: o contexto da Segunda Guerra Mundial influi no escritor, porque seu discurso se encontra imerso em uma situação social na qual México forma parte dos Aliados, junto a Estados Unidos, na contenda internacional.

Palavras clave: Análise do discurso, Relação México - Estados Unidos, Polifonia, Análise estilístico 


\section{Introducción}

Con la escritura, instrumento eficaz y ambivalente, se han declarado guerras y se han firmado tratados de paz (...) se ha ido acumulando y conservando una parte esencial de la memoria humana (...) las historias que nos ligan a nuestras raíces y muy especialmente, esas obras excelentes, quizá generosamente gratuitas, que son los escritos literarios, las elaboraciones estéticas del lenguaje, la creación de mundos posibles.

(J. Tusón, 1996, p. 9)

En plena Segunda Guerra Mundial, en los primeros meses de 1943, se registró la ofensiva contundente y decisiva de Estados Unidos e Inglaterra contra Alemania. La célebre conferencia en Casablanca (Marruecos) entre Franklin Delano Roosevelt, presidente de Estados Unidos, y Winston Churchill, primer ministro de Inglaterra, desembocó en la decisión de desembarcar en Sicilia y exigir la capitulación, sin condiciones, de Alemania. Paralelamente, las tropas rusas lograron rendiciones de ciudades alemanas. La decadencia del Tercer Reich era un hecho.

Casi al terminar abril (28) aconteció la insurrección del ghetto de Varsovia (Polonia). Unos 60 mil judíos, prácticamente sin más armas que su coraje y rebeldía interna, se levantaron contra los nazis durante un mes.

Mayo y junio de 1943 serían dramáticos para la humanidad: la rendición del "Afrika Korps". 252 mil soldados alemanes e italianos se rindieron en África del Norte y las potencias del Eje vieron inminente su derrota.

La situación de México, respecto de Estados Unidos, era contradictoria. Por una parte, existía un viejo litigio histórico que ponía en desventaja a México. Por otra, la situación internacional había provocado una adhesión de México hacia Estados Unidos. La agresión alemana a barcos mexicanos determinó la declaración de guerra de México hacia las potencias del Eje y la adhesión a Estados Unidos. El famoso Escuadrón 201 entró en acción en la Segunda Guerra Mundial, como una aportación de México al lado de los aliados.

Un joven escritor, José Revueltas (1914-1976), que contaba con 25 años -pero ya con un trabajo literario relevante (Los muros de agua, 1941) - es enviado por la revista $A s i ́$, a realizar una serie de reportajes y artículos de opinión, que al paso del tiempo se diluyeron y son prácticamente desconocidos. Gracias al acceso de la colección privada de la señora Belia Ortega Molina, hija del director de la revista Así, Gregorio Ortega, se pudieron recuperar diez textos periodísticos de Revueltas. Uno de ellos titulado Los intelectuales mexicanos frente a Norteamérica con el subtítulo Con los Estados Unidos de mañana, es analizado aquí por dos razones, principalmente: a) la trascendencia de la temática abordada en el artículo y b) porque revela, con 
trazos literarios y manejo del lenguaje periodístico, la posición de un escritor frente a la relación México-Estados Unidos. Revueltas destacó por su crítica al sistema, la independencia de criterio y su apego a principios ideológicos, que no aceptaban clichés ni cartabones de ningún tipo.

Revueltas mantuvo una crítica permanente hacia los políticos y los modos de hacer política, y total irreverencia hacia las mafias literarias. Además de una eterna ironía que expresaba su desencanto con el mundo que le tocó vivir. Sin embargo, el análisis del texto que aquí se presenta, manifiesta una faceta diferente del escritor y periodista autor de Los muros del agua, Los días terrenales, El luto humano, La diosa arrodillada y El apando, entre otros. Mantiene la ironía, pero abre una rendija a la esperanza.

Revueltas representó, literariamente, un ejemplo a seguir. Políticamente, un modelo de independencia que se opuso a toda forma de opresión. Su adhesión al Movimiento estudiantil de 1968 le costó ser aprehendido y llevado a la Cárcel de Lecumberri, donde sobrevivió en condiciones de tal precariedad que llegó a expresar: "Aquí (en la cárcel) se puede morir por un bolillo o un tornillo”. Uno de sus escritos más dramáticos, El apando, fue realizado en Lecumberri. Relata las características del apando, nombre con el que denominaban a una minúscula celda, a la que eran confinados los presos a quienes se consideraban que debían ser "apandados”.

$\mathrm{Su}$ vida tuvo varios sellos. Uno, su lealtad a las causas juveniles. Su identificación con los jóvenes era plena. Por eso, se les unió sin reservas, al grado de mudarse a la Facultad de Filosofía y Letras de la UNAM, donde era académico y ellos lo acogieron como guía intelectual.

Al referirse a la participación de su padre en el 68, Andrea Revueltas (citado por Leyva, 2003) opina que:

Creo que ese compromiso político de mi padre era natural, porque era una persona con ética; sólo aquel que cierra los ojos para no ver a sus alrededor puede ser indiferente ante la injusticia. En México la desigualdad ha sido siempre gigantesca, una minoría comparable a los núcleos más ricos del mundo y una de las pobrezas más dramáticas en el planeta. Yo creo que esa visión era la causa esencial de su compromiso político. Habrá quien se ciegue y prefiera la indiferencia, la inmovilidad. Mi padre no pudo ni quiso evitarlo y siguió el camino de su conciencia, de su sensibilidad y por lo mismo estuvo presente en los movimientos que le tocó vivir, como el de 1968 (Leyva, 2003, p. 151).

“¿Por qué José Revueltas, se convirtió en el guía político y espiritual del movimiento estudiantil y sus alrededores? En más de un sentido “era la encarnación de la rebeldía, de una voluntad férrea en perseguir la utopía socialista, de la coherencia de toda una vida de predicar con el ejemplo” (Luna, 2004, p. 33).

Esbozadas esas características de Revueltas, se plantean las siguientes preguntas: ¿Cuál fue la percepción de Revueltas frente a los retos y alcances de la vecindad de México con Estados Unidos? ¿Cómo desglosar el discurso de Revueltas ante esa temática? 
Las respuestas permitirán conocer el punto de vista de Revueltas, ante una relación polémica y con diferentes facetas por abordar. El análisis del artículo se justificaría en varios sentidos: uno de ellos, la postura de un intelectual independiente y su influencia en el medio intelectual de su época. Y otro, la vigencia de sus ideas, vistas a la luz de siete décadas después de haber sido escrito el artículo. Asimismo, la propia lectura del artículo muestra -vía el discurso de Revueltas- la clasificación de los intelectuales de la década de los cuarenta en México.

\section{Metodología}

El uso del análisis del discurso, como herramienta metodológica para analizar el artículo de opinión Los intelectuales mexicanos frente a Norteamérica y el subtítulo Con los Estados Unidos de mañana, de José Revueltas en 1943, resultó idóneo. Además, permitió ampliar significados y precisar forma y fondo. Los discursos escritos se han considerado, históricamente, como prácticas sociales ligados a cada cultura y a cada sociedad. Calsamiglia y Tusón (1991), consideran al respecto que:

El discurso es socialmente constitutivo así como es socialmente constituido: constituye situaciones, objetos de conocimiento, identidades sociales y relaciones entre personas y grupos de personas. Es constitutivo tanto en el sentido de que ayuda a mantener y reproducir el statu quo, como en el sentido de que constituye a transformarlo (p.3).

El discurso, afirma Karam (2010), se ha convertido en un término que traspasa fronteras disciplinarias.

No es reducible a un ámbito específico, y su alusión puede servir para explicar fenómenos sumamente amplios. La palabra discurso, suele ser entendida como "texto". Genéricamente se establecen algunas diferencias entre el "texto" como "la manifestación concreta del discurso”, "el producto en sî” y el “discurso” se entiende como "todo el proceso de producción lingüística que se pone en juego para producir algo" (p.15)

En el análisis de un texto, desempeña un papel relevante la elección semántica que realiza el locutor, entendido éste como el sujeto que sostiene la voz; es decir, el responsable de lo que ahí se expresa. Esa elección, acotan Calsamiglia y Tusón (1999, p. 4) se realiza

De acuerdo con unos parámetros contextuales que incluyen la situación, los propósitos de quien la realiza y las características de los destinatarios. Estos parámetros son de tipo cognitivo y sociocultural, son dinámicos y pueden estar sujetos a revisión, negociación y cambio (p. 5). 
Se reflexionó en el papel del contexto en el cual fue escrito el artículo de Revueltas y su impacto en la elección de la temática y en la forma de tratar el discurso. Se coincide con Calsamiglia y Tusón (1999, p.18) quienes afirman:

Si bien un texto proporciona un material valioso para la interpretación del significado en la comunicación, ese material, para ser interpretado cabalmente, necesita la contribución de los elementos aportados por el contexto [ ...] los elementos del contexto, tanto si pertenecen a otros códigos semióticos como si pertenecen a sobreentendidos e implícitos, constituyen el fondo de interpretación de los elementos verbales, a través de las pistas e indicios, aportados por los propios hablantes y que contribuyen a construir el contexto adecuado.

En el análisis del texto de Revueltas se utilizó un modelo basado en las ideas de Osvald Ducrot (2010), Prieto (2000) y Calsamiglia y Tusón (1998). El análisis estuvo permeado por el contexto de la época, en cuyo marco Revueltas reflexiona sobre los alcances de la relación México-Estados Unidos, con una apertura inimaginable en otra etapa de la historia de la vecindad entre ambos países.

Ducrot (2010), concibe la polifonía como una técnica consistente en incluir en el propio discurso el de otros actores, para apuntalar, desvirtuar o desvanecer un argumento. Es decir, no siempre la polifonía es para adherirse al discurso de otra persona, sino para alejarse o incluso abandonar determinadas ideas. Para Ducrot (2010)

El decir es como una representación teatral, como una polifonía en la que hay una presentación de diferentes voces abstractas, de varios puntos de vista y cuya pluralidad no puede ser reducida a la unicidad del sujeto hablante (p. 33).

El concepto de unicidad es dejado a un lado y sustituido por el de los "seres del discurso", como los llama Ducrot (2010), los cuales son el sujeto empírico (el productor del enunciado); el locutor, a quien se atribuye la responsabilidad del enunciado y de la enunciación de éste y los enunciadores, que corresponden a los orígenes de los diferentes puntos de vista que se expresan a través de la enunciación (Jiménez, 2013).

Los tipos de textos polifónicos, el discurso reproducido, los enunciados llamados "ecoicos" y los intertextos son utilizados en el análisis del texto de Revueltas. De Prieto (2000) se tomaron algunas categorías de su modelo de análisis estilístico, tales como la magnificación, la universalización y la vía del ejemplo. La primera consiste en destacar lo ya subrayado explícitamente en el texto a través de términos totalizadores como "jamás", "siempre", "nunca".

Asimismo, se usó la categoría de la universalización, consistente en generalizar situaciones y la vìa del ejemplo, utilizada para apuntalar con ejemplos lo dicho.

Desde el punto de vista gramatical, se ubicó el uso del sustantivo abstracto cuya finalidad es otorgar a determinada expresión una visión más amplia. Se buscó también ubicar el uso de la ironía. Según Ducrot (2010, p. 33), la singularidad de la 
ironía se ubica en que el sujeto hablante "presenta una actitud de distanciamiento" de determinada situación presentada.

Afirmar que una respuesta es irónica equivale a decir que para interpretarla es preciso homologar con dos personas diferentes al locutor de la enunciación y el enunciador que se expresa en esa enunciación $[\ldots]$ en la ironía se dice una cosa, pero quiere decirse otra, la contraria, afirma Ducrot (citado por Jiménez, 2013).

Según Jiménez (2013) “no hay marca textual”. La ironía se deduce por el contexto y el conocimiento de las cosas. "Se trata de un fenómeno metapragmático y queda claro que en la ironía se da una pluralidad de voces: la que lo dice literal y la que se hace responsable” (Jiménez, 2013). Sin embargo, en este parte del análisis se tomó el uso de las comillas para denotar ironía puesto que ellas, en ciertos casos, equivalen a la expresión de duda o incluso burla.

En cuanto al análisis estilístico propuesto por Prieto (2000) se tomaron las categorías de magnificación, universalización y la vía del ejemplo. La primera, utilizada por el responsable del discurso, en este caso Revueltas, para dar una amplitud mayor a su dicho. La segunda, vinculada con la primera para asignar un valor radical a sus expresiones. Y la tercera, la vía del ejemplo, para otorgar al lector los ejemplos suficientes que avalen su discurso.

El trabajo de análisis se realizó a través de la lectura completa del texto, enseguida se marcó con negritas los elementos que denotaron tal o cual categoría y posteriormente se hizo un ejercicio cuantitativo entre las categorías encontradas. El aspecto cualitativo se llevó a cabo al vincular las categorías e interpretar las mismas.

\section{Resultados}

Revueltas inicia su artículo titulado Los intelectuales mexicanos frente a Norteamérica y el subtítulo Con los Estados Unidos de mañana, reflexionando en que la vecindad entre ambos países "no se ha comprendido del todo ni en México ni en Norteamérica." A través de la categoría de la magnificación, Revueltas presenta un panorama crítico de la relación entre México y Norteamérica al iniciar su texto y exponer que "no se ha comprendido la vecindad entre ambas naciones "del todo ni en México ni en Norteamérica. Más adelante el escritor "jamás”, "histórica”, “siglos”, “siempre”. Asienta:

Jamás hemos profundizado lo suficiente en el hecho de que es una vecindad histórica, forzosa, que durará siglos a menos que ocurra una catástrofe. Y de ahí, de esa circunstancia geográfica e histórica - del hecho indudable de que siempre los mexicanos sabrán que al norte se encuentra un país llamado Norteamérica, y de que los norteamericanos sabrán siempre que al sur hay un país llamado México-, debemos deducir una revisión de nuestras respectivas actitudes, para adoptar por ambas partes un criterio positivo. 
Empero, junto al tono fatalista que imprime Revueltas a esta primera parte de su texto, deja un breve paso a la esperanza de que las cosas no sean tan oscuras como las pinta. Al referirse a la vecindad México-Estados Unidos, plantea inicialmente que “jamás hemos profundizado”. Sin embargo, enseguida matiza "lo suficiente” en el hecho de que es una vecindad "histórica, forzosa que durará siglos y enseguida vuelva a amainar "a menos que ocurra una catástrofe". Luego, plantea realidades contundentes para deducir que en esa relación, entre ambos países, “debemos deducir una revisión de nuestras respectivas actitudes, para adoptar por ambas partes un criterio positivo".

Al continuar su artículo, Revueltas escribe:

Los artistas mexicanos están empeñados en la actualidad en la gigantesca obra de contribuir a la formación de una "cultura mexicana”. Esta obra que ocupará a varias generaciones, es el anhelo y la preocupación más onda del artista mexicano actual. Los artistas de México que tienen respeto por su propio trabajo, se esfuerzan por realizar un mestizaje, dentro de las mejores condiciones de creación e inspiración auténticas, entre la cultura occidental y la cultura indígena, desechando, de paso, los aspectos no válidos de ambas.

El escritor usa la categoría de la generalización al inicio del párrafo anterior (los artistas mexicanos) y da la impresión de que son mayoría quienes "están empeñados" en una obra que califica de "gigantesca”, cuyo objetivo es formar una "cultura mexicana”. Más adelante, sin embargo, acota que "los artistas de México que tienen respeto por su propio trabajo" trabajan en realizar un mestizaje que rescate las mejores características de las culturas occidental e indígena. Más adelante usa la categoría del ejemplo, al explicar:

Esta obra, que inició la Colonia Española con la arquitectura de los siglos XVI y XVII, ha sido continuada por nuestros pintores, cuyo magnífico arte es un producto legítimo de la tradición hispano-indígena del país. Pero naturalmente, el propósito de realizar una síntesis de tal magnitud, originó en los artistas mexicanos inevitablemente una cierta actitud defensiva hacia la parte no latina, de la cultura occidental, es decir, hacia la parte anglo-sajona de dicha cultura. Un libro de Georges Duhamel, Escenas de la Vida Futura, fue considerado durante algún tiempo como una especie de credo por los artistas más jóvenes, que veían en él una declaración de principios de la sensibilidad latina en contra de las asperezas, vulgaridad e inhumanidad del maquinismo. El intelectual mexicano, de esta suerte, terminó por realzar las distinciones entre cultura y civilización, quedándose con la primera. Los Estados Unidos apreciaron ante su vista, entonces, no como un país culto, sino como un país civilizado y más aún, como un país capaz de civilizar todo, es decir, de arrancarle el espíritu a cualquier cosa. En rigor todavía muchos intelectuales juzgan a los Estados Unidos como un país mecánico, ciego, en persecución de locas quimeras civilizadas que le hacen olvidar la esencia y le impiden la contemplación impostergable requerida por todo arte y por toda filosofía. 
En el párrafo anterior, Revueltas utiliza la polifonía al integrar a su discurso el pensamiento de Georges Duhamel y lo que podría denominarse polifonía múltiple, ya que da por hecho que los artistas jóvenes veían en el libro de Duhamel Escenas de la vida futura, "una especie de credo $\{\ldots\}$ una declaración de principios de la sensibilidad latina en contra de las asperezas, vulgaridad e inhumanidad del maquinismo".

El discurso elaborado y cuidadoso de Revueltas integra el uso del sustantivo abstracto con habilidad y destreza como se advierte en las últimas dos líneas del párrafo anterior al expresar que hay una sensibilidad latina "en contra de las asperezas, vulgaridad e inhumanidad del maquinismo."

La estructura del artículo de Revueltas manifiesta también un sentido didáctico al explicar y ejemplificar sus opiniones. Según el escritor, los intelectuales mexicanos sustentan tres grupos diferentes de opiniones:

El primero está constituido por los escritores "revolucionarios". El término "escritor revolucionario", está usado aquí en su sentido más general: no indica ninguna tendencia ideológica o política, sino simplemente el hecho de que en México se considera como "escritor revolucionario" al que escribe sobre la Revolución Mexicana de 1910 o al que participó en ella, aunque escriba en contra de sus principios o haya participado con grupos puramente episódicos y sin calidad histórica.

En el párrafo anterior contiene cierta dosis de ironía al usar las comillas para poner en duda que los llamados escritores revolucionarios, realmente lo sean. Más adelante explica su posición. Se les llama así, considera, a quienes escriben sobre la Revolución Mexicana de 1910 “o al que participó en ella, aunque escriba en contra de sus principios o haya participado con grupos puramente episódicos y sin calidad histórica”.

Un elemento que destaca Revueltas para denotar ironía es el uso del diminutivo y superlativo. Redacta:

Sobre el particular es curiosísimo el caso del doctor Mariano Azuela, cuya famosa obra "Los de Abajo" - sin duda uno de lo más vigorosos relatos de la Revolución-, le valió se considerara dentro de los “escritores revolucionarios”, pese a que su ideología no puede ser más conservadora. Hay que agregar, también, que los “escritores revolucionarios” constituyen las más diversas y aún opuestas tendencias literarias, con lo que se explica el uso del término como una forma de agrupar a los escritores reunidos en torno de una efeméride histórica, aunque no de un movimiento ideológico y doctrinario.

Tras señalar la incongruencia de considerar a Mariano Azuela como "escritor revolucionario", pese a tratarse de un personaje conservador, dice que el término se explica "como una forma de agrupar a los escritores reunidos en torno de una efeméride histórica”, aunque no de un movimiento ideológico y doctrinario. 
Pese a la crítica a Azuela, reconoce que los escritores considerados "revolucionarios" tienen una serie de virtudes. Entre ellas

La de que, ventajosamente en relación con los escritores de la generación pasada (Gutiérrez Nájera, Nervo, etc.), supieron volver los ojos hacia el propio país, descubriendo que tenían una nacionalidad y una patria. Liquidaron para siempre el "europeísmo" trasnochado que apenas sí cuenta en la actualidad con algunos pobres ejemplares de café. Junto a esta virtud, trajeron, no obstante, un pecado original de exageración y xenofobia. Terminaron por considerar a México como una isla orgullosa que no necesitaba para nada de la "cultura extranjera" ni de los viejos maestros de la cultura occidental. Fracciones de esa clase de escritores, falsos izquierdistas en lo político, además, llegaron a agruparse en un "Bloque de Obrero Intelectuales", levantándose contra las "Ideas de Moscú" desde su revista "Crisol”, con lo cual le hacían el juego a la dictadura derechista del general Calles que necesitaba por entonces de un cierto ropaje intelectual. Elementos como los del Bloque de Obreros Intelectuales -los cito porque constituyeron el núcleo más típico-, consideraban a la Revolución Mexicana como un fenómeno exclusivo de México y, calculando como cualquier ropavejero, decían que nuestra Revolución, por haberse iniciado en 1910, mientras la rusa sólo comenzó en el 17, era más importante y que en consecuencia nada tenía que aprender nuestro pueblo de "ese movimiento extranjero".

En el párrafo anterior se expresa un ejemplo de polifonía múltiple, al incorporar diversas voces en diversos sentidos. Por una parte destaca la posición de escritores como Manuel Gutiérrez Nájera y Amado Nervo que reivindicaron lo propio "descubriendo que tenían una nacionalidad y una patria”, pero a la vez Revueltas da a conocer sus propios prejuicios al afirmar que esos escritores "liquidaron para siempre el 'europeìsmo' trasnochado que apenas sí cuenta en la actualidad con algunos pobres ejemplares de café”.

Pero Revueltas, también hace notar que los escritores aludidos, trajeron un pecado original de exageración y xenofobia” y “terminaron por considerar a México como una isla orgullosa que no necesitaba para nada de la "cultura extranjera" ni de los viejos maestros de la cultura occidental. Agrega:

Fracciones de esa clase de escritores, falsos izquierdistas en lo político, además, llegaron a agruparse en un "Bloque de Obrero Intelectuales", levantándose contra las "Ideas de Moscú" desde su revista "Crisol”, con lo cual le hacían el juego a la dictadura derechista del general Calles que necesitaba por entonces de un cierto ropaje intelectual.

La ironía en el párrafo anterior se expresa en el uso de las comillas tanto al referirse a la denominación del grupo de intelectuales como al referirse a las "ideas de Moscú”. Más adelante sigue usando las comillas al calificar a los escritores "revolucionarios" en general, y le da a la ironía un matiz al afirmar que se “desentienden” de la existencia de Norteamérica y creen que así se defiende el país contra el "peligro yanqui”. He aquí el párrafo: 
Los escritores "revolucionarios" en general y como desentendiéndose de la existencia de Norteamérica, exaltan todo lo mexicano, acríticamente y tal vez juzgando que ésa es la forma de defensa que tiene el país en contra del "peligro yanqui”.

El uso magistral de la polifonía que lleva a cabo Revueltas para apuntalar sus opiniones es visible, aunque también la usa para alejarse o criticar a algunos autores, como se muestra al referirse al escritor Jorge Ferretis. La ironía se expresa cuando escribe que Ferretis defiende "conmovido" "ciertas costumbres feudales de nuestro país que contrastan con las modernas costumbres norteamericanas”. El fragmento es el siguiente:

Para ellos México constituye todo y aún sus defectos resultan virtudes y motivo de emoción, como por ejemplo las fusilatas y la ley fuga. Pueden citarse al muy apreciable novelista Jorge Ferretis, que en su libro Cuando engorda el Quijote, aprovecha el relato de un viaje a los Estados Unidos, para defender, conmovido, ciertas costumbres feudales de nuestro país que contrastan con las modernas costumbres norteamericanas.

La polifonía de Revueltas es singular. Incluye en su discurso a escritores con nombre y apellido y en varias categorías a intelectuales y políticos del momento sin mencionar sus nombres y agrega una categoría única: el pueblo. Entre las clasificaciones de intelectuales señala a "los revolucionarios" de quienes opina así:

Los “revolucionarios” - de la literatura o de la política- no ignoran a lo que nos obliga, en todos los terrenos, en el de la Cultura, en el de la Economía, la presencia en nuestra historia presente y en la del porvenir, de los Estados Unidos, pero hacen como si lo ignorasen -se hacen "como que la Virgen les habla", para usar un giro de pueblo-, y prefieren entonces soslayar el problema, evitarlo, creando al mismo tiempo lo que en el futuro puede convertirse en un "fascismo cultural" de la peor especie.

Califica a otra categoría, la de "los hispanistas" un grupo de intelectuales cuya actitud "es aún más perniciosa” que la de "los revolucionarios”. Además, señala "que no registran en sus filas ningún valor intelectual profundo, fuera de José Vasconcelos, uno de los talentos más arbitrarios y a la vez más seductores de México”. Al calificar a Vasconcelos, maneja de manera muy atractiva los adjetivos al señalar a ese intelectual como "arbitrario" y "seductor".

Los "hispanistas" consideran que todo lo malo le llega al país de los Estados Unidos. Conforme a los "hispanistas" debemos defender a ultranza, todo lo hispano de nuestra cultura, e inclusive todo lo anti-indígena de la penetración española. Llegan a identificar de tal modo a la Iglesia Católica con la cultura de España y por ende, desde su punto de vista hispanófilo, con la nacionalidad mexicana, que preconizan un retorno a la Época Colonial, retorno que comprendería no sólo la cultura, sino 
también la organización política y económica que reinó bajo los virreyes. Los libros de Vasconcelos están destinados a propagar tal doctrina bajo el muy discutible ropaje de una confusa filosofía basada en la "raza cósmica", que con el ingrediente español sería el vaso de una síntesis de la cultura universal. El resultado del pensamiento "hispanista" ha sido, por lo pronto, la formación de dos partidos reaccionarios y fascistas: la Unión Sinarquista y Acción Nacional.

Usando la vía del ejemplo, Revueltas explica que el hispanismo está constituido por una mezcla de sentimientos aristocráticos entre los que predomina "cierto asco horrorizado frente a la psicología del pueblo" y que en el fondo estos sentimientos comprenden admiración hacia lo extranjero y terminan por convertirse "en un servilismo auténtico hacia los poderes imperialistas, sean latinos o anglosajones”. De esta manera, sostiene que:

Hemos tenido en el país como único fruto, un imperio de Maximiliano, llevado a México por los hispanistas de aquel tiempo, o una República de Texas, presidida por Lorenzo de Zavala, intelectual que en su hora también sintió el "hispanista" horror hacia los defectos del pueblo mexicano.

Englobada en la categoría de “jóvenes intelectuales”, Revueltas incluye a "una minoría intelectual, compuesta en su mayor parte por jóvenes” que, en su opinión, "entiende con justeza el problema de la vecindad con los Estados Unidos y el problema de la serie de elementos que se derivan de esta vecindad.”

Confía que "probablemente" en Estados Unidos "también sean minoría los que comprendan, justamente el problema de la vecindad con México.”

Y advierte: "En todo caso, ambas minorías no pueden trabajar la una sin la otra, no pueden luchar sin tenderse la mano, sino por su punto de vista en su propio país, con todas las fuerzas y con toda la intrepidez".

En su argumentación, Revueltas incluye una cuarta categoría: el pueblo, y sin explicar quiénes integran esta categoría, engloba en ella a "una minoría de intelectuales revolucionarios sin comillas”. Expresa que:

Lo importante de esa minoría intelectual de México es que, si bien no todos los intelectuales piensan como ella, el pueblo, en cambio, sí tiene su mismo criterio. La minoría a que me refiero, que es una minoría de intelectuales revolucionarios sin comillas, entiende que ni México ni los Estados Unidos son países aislados y que ambos tienen, de igual a igual y con sus propios recursos, el deber de enfrentarse, junto con otros pueblos, a la tarea de crear un mundo nuevo para la humanidad. Esto plantea, como obra parcial dentro de la gran obra renovadora del mundo en la post-guerra, la de nuestras relaciones culturales de país a país, de pueblo a pueblo, de artistas a artistas, de pensadores a pensadores.

Revueltas expone sus ideas de concordia entre ambos países y, a través de la inclusión, expresada en la primera persona del plural, considera, de manera abarcadora, que es posible establecer "una cultura americana con la mexicana" 
En México imaginamos como posible la comunión de la cultura americana con la mexicana; imaginamos como posible la existencia de un cierto contrapunto armónico entre las dos sensibilidades.

Revueltas utiliza la vía del ejemplo y la polifonía al incluir una declaración de José Stalin en el sentido de que el bolchevismo era la alianza "del ímpetu revolucionario ruso y del practicismo amercano”. Para Revueltas esa combinación daba resultados "sorprendentes". Escribe:

Ningún observador superficial hubiese creído por ejemplo, que Stalin, siendo un hombre que conoce tanto a su país, hablara algún día como lo hizo, de que el bolchevismo es la alianza "del ímpetu revolucionario ruso y del practicismo americano”. Sin embargo, la moderna Unión Soviética, con sus grandes fábricas, con su gran industria, con su extraordinario movimiento cultural y con su prodigiosa defensa, está demostrando que si a un ímpetu humano, que si a una emoción verdadera, que si a una fantasía, se les agrega ese "practicismo americano", los resultados son sorprendentes.

Deduce el escritor que ese "practicismo americano" puede incluirse también en México y aliar el espíritu nacional con el practicismo de los vecinos del norte. La visión optimista de Revueltas se expresa con el remate a la posible alianza MéxicoEstados Unidos, al calificar el "practicismo norteamericano" como "síntesis del genio nacional de Norteamérica”.

La parte de los intelectuales mexicanos que se coloca en el punto de vista más universal, acepta como un hecho futuro e inevitable, la alianza de nuestro espíritu nacional, de nuestro temperamento imaginativo, de nuestra profundidad estética, con el "practicismo norteamericano", entendido éste como síntesis del genio nacional de Norteamérica.

Sin embargo, el optimismo esperanzador de Revueltas se ve matizado por la cautela cuando pregunta sobre la clase de "practicismo norteamericano" que nosotros queremos en México? Y aclara que:

Desde luego que no es el "practicismo norteamericano" de los negociantes de la Staudart Oil; ni el rudo practicismo de los marinos yanquis en Nicaragua. Los mexicanos conscientes respetan y quieren a los Estados Unidos de hoy; a esos que con su "practicismo norteamericano" movilizan a los trabajadores para producir implementos contra los militaristas japoneses en China y el Pacífico, y contra los fascistas en Rusia.

Enseguida, Revueltas presenta una proyección al afirmar que "los mexicanos conscientes aman mucho más a los Estados Unidos del futuro.” Para explicar enseguida a qué se refiere al decir eso e incluirse él mismo con la primera persona del plural. 
Valles Ruiz, Rosa María (2014). Retos y alcances de la vecindad de México con Estados Unidos. Mirada desde el escritor mexicano José Revueltas. Ánfora, 21(36), 67-90. Universidad Autónoma de Manizales. ISSN 0121-6538.

En esos Estados Unidos del futuro estamos empeñados, los mexicanos y los norteamericanos.

De nuevo cauteloso, pero sin perder el tono de optimismo esperanzador, Revueltas aclara:

Tal vez hoy tan sean sólo minorías de Estados Unidos y de México las que comprendan el problema de nuestro futuro común -más esencial que nuestro presente, pero por el que debemos luchar desde hoy mismo-, y para nosotros resulta prodigioso el imaginarnos lo que pueden llegar a ser los Estados Unidos cuando se convierten en un país sin discriminaciones raciales, sin plutocracia, sin pandillas imperialistas. Pero el que así sea es una tarea común de los intelectuales de México y Estados Unidos, siempre al lado de sus pueblos.

En la última parte de su artículo, José Revueltas hace uso de una polifonía que podríamos denominar "del prestigio moral". Al referirse a escritores connotados de Estados Unidos les atribuye haber contribuido para dar a conocer "la nueva sensibilidad norteamericana”. Se advierte que de la misma forma como destaca la valía de esos escritores, desconfía de uno de ellos, Ernest Hermingway. He aquí el fragmento:

Creemos en la nueva sensibilidad norteamericana. En México han contribuido a descubrírnosla escritores tales como Teodoro Dreiser, Sherwood Anderson, William Faulkner, John Steinbeck, Richard Rigth (no cito a Ernest Heminway porque desconfío de los bestsellers sobre todo después de haberlos leído), y en otro orden Sinclair Lewis y John Dos Pasos, cuyas obras, saturadas de generosidad y de impulso, nos muestran el hecho espléndido de que nuestro sufrido, triste, ardiente pueblo mexicano, tiene hermanos, igualmente pobres, sufridos y llenos de esperanza en Norteamérica.

El cierre del artículo de Revueltas es magistral. A través de la inclusión del propio escritor, la polifonía y un estilo literario atractivo, remata:

Ese país entrañable de Faulkner o Steinbeck, de Anderson o Rigth, es el que amamos. Además es el país con el que marcharemos lado a lado, mañana, cuando la aurora brille sobre el abatido cielo de la humanidad.

\section{Conclusiones}

El artículo Los intelectuales mexicanos frente a Norteamérica. Con los Estados Unidos de mañana, del escritor mexicano José Revueltas, escrito hace más de 70 años, muestra una problemática histórica: la vecindad entre México y Estados Unidos, matizada por el contexto de la época significada por la Segunda Guerra Mundial.

Este marco internacional y el hecho de que México participara en la Segunda Guerra Mundial, al lado de los países Aliados, con Estados Unidos, Inglaterra y 
Francia, establece, en parte, el tono del artículo de Revueltas. Éste, hace ver el determinismo de la situación geográfica de ambos países y la necesidad inminente de reconocer y respetar las características de ambas naciones, en aras de una convivencia civilizada. Se manifiesta, contrario, a las posturas extremas de quienes, por una parte, aborrecen al vecino del norte y, por otra, de quienes sólo ven grandes virtudes en Estados Unidos.

El análisis presentado aquí, tomando como instrumento metodológico el análisis del discurso representa un enfoque diferente respecto de otros análisis. En el artículo titulado "José Revueltas: humillado y ofendido (primera recepción de Los errores 1964-1966)” Sonia Adriana Peña (2010, p.1) reseña el libro Los errores no sólo en el contenido, sino en las dedicatorias e incluso el epígrafe. Registra los puntos de vista de otros escritores sobre el texto. Si puede hablarse de similitudes entre el artículo analizado aquí y Los errores es que ambos manifiestan una postura ideológica sobre la temática abordada aunque los separa la distancia en casi veinte años en que fueron escritos. En Los intelectuales mexicanos frente a Norteamérica, se advierte un Revueltas crítico respecto del quehacer literario de su época en tanto en Los errores el tono es como lo apunta Peña (2010, p.2) sarcástico respecto de la actitud del Partido Comunista Mexicana (PCM) del cual fue expulsado Revueltas. Una diferencia esencial entre ambos textos es que Los intelectuales es un artículo de opinión periodístico en tanto Los errores es una novela.

Respecto del instrumento metodológico utilizado para analizar Los intelectuales destaca como pertinente la adhesión a los planteamientos de Malinovski, Helena Calsamiglia y Amparo Tusón al llevar a cabo un análisis del discurso como herramienta metodológica para analizar el texto de Revueltas, el cual, 70 años después de haber sido escrito, adquiere relevancia y vigencia.

Asimismo, el uso de la categoría de polifonía, en diversas modalidades, planteado por Osvald Ducrot, fue de gran utilidad. En el discurso de Revueltas, el uso polifónico, permitió registras categorías como la que podemos denominar "polifonía del prestigio" en la cual el locutor incluye y sostiene la voz de intelectuales de gran valía y prestigio internacional. Revueltas incluye la estatura intelectual de escritores como John Steinbeck, John Dos Pasos, William Faulkner, Rigth y les asigna un sitial de relevancia como intelectuales norteamericanos. Paralelamente usa lo que podría llamarse "polifonía del desprestigio" al incluir a otro intelectual norteamericano reconocido pero con el que no coincide. En este caso se refiere a Ernest Hemingway y lo cita aunque en sentido negativo, al expresar "no cito a Ernest Heminway porque desconfío de los bestsellers sobre todo después de haberlos leído". El concepto "polifonía del prestigio” y "polifonía del desprestigio" puede agregarse a los conceptos ya conocidos en el uso de la polifonía.

La ironía, manejada magistralmente por el escritor, se expresa al clasificar a los intelectuales mexicanos en varias categorías (revolucionarios, hispanistas, etc.) y 
agregar -sin una precisión certera- la categoría de "pueblo" a la que se adhiere y acota que "una minoría" de intelectuales también se engloba en la misma. Esa ironía se manifiesta al poner en duda la propia clasificación que usa. Por ejemplo, afirma que se consideran "revolucionarios" aquellos que escriben sobre esa etapa sin comprometerse ideológicamente con alguno de los principios que sostuvo la Revolución Mexicana. De la ironía, pasa a la crítica directa al referirse a Mariano Azuela, autor de la novela Los de abajo, a quien considera Revueltas un personaje conservador.

Esta forma de clasificación de Revueltas sobre los intelectuales no se ajusta específicamente a las categorías teóricas que se manejan en este artículo. Es evidente que su clasificación sobre los intelectuales está relacionado directamente con el plano ideológico el cual expresa a través de la ironía, es decir, con un dejo de escepticismo sobre todo a los que engloba como "revolucionarios" porque, como dice, se incluyen en esa categorías a quienes escriben sobre el tema no a quienes de adhieren a los principios de la Revolución Mexicana.

Una reflexión final derivada del análisis. La postura de Revueltas frente a las relaciones México-Estados Unidos es de reconciliación, de encuentro y de reconocimiento de los valores de la sociedad norteamericana, pese a la histórica relación con aristas de conflicto.

El uso del análisis estilístico con base en la propuesta de algunas categorías de Daniel Prieto Castillo fue adecuado para ubicar semánticamente el uso hecho por Revueltas de la magnificación, la universalización y la vía del ejemplo. Esta última destacó al ejemplificar diversos aspectos.

\section{Referencias}

Calsamiglia, H. y Tusón, A. (2000). Las cosas del decir, Barcelona, Ariel.

Ducrot, O. (2010). El decir y lo dicho. Barcelona: Ariel.

Karam, T. (2005). Una introducción al estudio del discurso y al análisis del discurso Global Media Journal (2). Recuperado de: http://www.redalyc.org/articulo. oa? id $=68720305$

Leyva, J.A. (2003). El naranjo en flor. Homenaje a los hermanos Revueltas, México, ICED

Luna, A. (2004). “José Revueltas o la utopía contrariada” en Alberto Saladino García (compilador), Humanismo mexicano del siglo XX (Tomo I), Toluca, Universidad Autónoma del Estado de México, 2004, págs. 411-420.

Disponible en http://www.ensayistas.org/critica/generales/C-H/mexico/ revueltas.htm 
Peña, Sonia Adriana. (2010). José Revueltas: humillado y ofendido (recepción inicial de Los errores, 1964-1966). Península, 5(1), 119-133. Recuperado el 22 de abril de 2014, de http://www.scielo.org.mx/scielo.php? script=sci_ arttext\&pid=S1870-57662010000 $100005 \& \operatorname{lng}=\mathrm{es} \& \operatorname{tlng}=\mathrm{es}$.

Prieto C. (2000). La fiesta del lenguaje, México: Edamex

Revista Así. Número 149, 18 septiembre 1943. Archivo personal de la Sra. Belia Ortega Molina 


\title{
Anexo
}

\section{Los intelectuales mexicanos frente a Norteamérica Con los Estados Unidos de mañana}

Por José Revueltas

Redactor de ASI

(Núm. 149, 18 septiembre 1943)

\begin{abstract}
La desgracia de México es estar muy lejos de Dios y muy cerca de los Estados Unidos, decía don Porfirio - pero jamás hemos profundizado lo suficiente en el hecho de que es una vecindad histórica, forzosa, que durará por todos los siglos de los siglos.
\end{abstract}

Se atribuye al viejo dictador de México, Porfirio Díaz, una frase carente de originalidad y al mismo tiempo falta de razón. "La desgracia de México -afirmaba don Porfirio-, es estar muy lejos de Dios y muy cerca de los Estados Unidos”. No obstante, la guerra de hoy contra un común enemigo, ha demostrado que esa pretendida desgracia constituye por el contrario, una gran aventura para México y para los Estados Unidos. Muchos mexicanos se felicitan en actualidad de que la contradicción inevitable y el inevitable encuentro de intereses opuestos entre México y los Estados Unidos se hayan resuelto dentro de una fórmula de cooperación. Pero también lo que se preguntan esos mismos mexicanos, es justamente si la cooperación no significa una mera fórmula del momento y si dejará de ser un hecho real y tangible para el futuro. Esta pregunta no debe de ser contestada por el pueblo americano solo, sino por los dos pueblos juntos, pues es un problema de los propios pueblos más que de los gobernantes o políticos del día.

Precisa desde luego, reconocer que la cuestión de la vecindad MéxicoNorteamericana - no de la buena o mala vecindad, sino únicamente de la vecindad en sí-, no se ha comprendido del todo ni en México ni en Norteamérica. Jamás hemos profundizado lo suficiente en el hecho de que es una vecindad histórica, forzosa, que durará siglos a menos que ocurra una catástrofe. Y de ahí, de esa circunstancia geográfica e histórica - del hecho indudable de que siempre los mexicanos sabrán que al norte se encuentra un país llamado Norteamérica, y de que los norteamericanos sabrán siempre que al sur hay un país llamado México-, debemos deducir una revisión de nuestras respectivas actitudes, para adoptar por ambas partes un criterio positivo. 


\section{Tarea gigantesca}

Los artistas mexicanos están empeñados en la actualidad en la gigantesca obra de contribuir a la formación de una "cultura mexicana”. Esta obra que ocupará a varias generaciones, es el anhelo y la preocupación más onda del artista mexicano actual. Los artistas de México que tienen respeto por su propio trabajo, se esfuerzan por realizar un mestizaje, dentro de las mejores condiciones de creación e inspiración auténticas, entre la cultura occidental y la cultura indígena, desechando, de paso, los aspectos no válidos de ambas.

Esta obra, que inició la Colonia Española con la arquitectura de los siglos XVI y XVII, ha sido continuada por nuestros pintores, cuyo magnífico arte es un producto legítimo de la tradición hispano-indígena del país. Pero naturalmente, el propósito de realizar una síntesis de tal magnitud, originó en los artistas mexicanos inevitablemente una cierta actitud defensiva hacia la parte no latina, de la cultura occidental, es decir, hacia la parte anglo-sajona de dicha cultura. Un libro de Georges Duhamel, Escenas de la Vida Futura, fue considerado durante algún tiempo como una especie de credo por los artistas más jóvenes, que veían en él una declaración de principios de la sensibilidad latina en contra de las asperezas, vulgaridad e inhumanidad del maquinismo. El intelectual mexicano, de esta suerte, terminó por realzar las distinciones entre cultura y civilización, quedándose con la primera. Los Estados Unidos apreciaron ante su vista, entonces, no como un país culto, sino como un país civilizado y más aún, como un país capaz de civilizar todo, es decir, de arrancarle el espíritu a cualquier cosa sustituyéndolo por un ersatz cualquiera. En rigor todavía muchos intelectuales juzgan a los Estados Unidos como un país mecánico, ciego, en persecución de locas quimeras civilizadas que le hacen olvidar la esencia y le impiden la contemplación impostergable requerida por todo arte y por toda filosofía.

\section{Tres grupos de opiniones}

Los intelectuales mexicanos de hoy, sustentan al respecto tres grupos diferentes de opiniones. El primero está constituido por los escritores “revolucionarios”. El término "escritor revolucionario”, está usado aquí en su sentido más general: no indica ninguna tendencia ideológica o política, sino simplemente el hecho de que en México se considera como "escritor revolucionario" al que escribe sobre la Revolución Mexicana de 1910 o al que participó en ella, aunque escriba en contra de sus principios o haya participado con grupos puramente episódicos y sin calidad histórica. Sobre el particular es curiosísimo el caso del doctor Mariano Azuela, cuya famosa obra "Los de Abajo" -sin duda uno de lo más vigorosos relatos de la Revolución-, le valió se considerara dentro de los "escritores revolucionarios", pese a que su ideología no puede ser más conservadora. Hay que agregar, también, 
que los "escritores revolucionarios" constituyen las más diversas y aún opuestas tendencias literarias, con lo que se explica el uso del término como una forma de agrupar a los escritores reunidos en torno de una efeméride histórica, aunque no de un movimiento ideológico y doctrinario.

\section{Los revolucionarios}

Los escritores "revolucionarios" tienen una serie de virtudes, entre ellas la de que, ventajosamente en relación con los escritores de la generación pasada (Gutiérrez Nájera, Nervo, etc), supieron volver los ojos hacia el propio país, descubriendo que tenían una nacionalidad y una patria. Liquidaron para siempre el "europeísmo" trasnochado que apenas sí cuenta en la actualidad con algunos pobres ejemplares de café. Junta a esta virtud, trajeron, no obstante, un pecado original de exageración y xenofobia. Terminaron por considerar a México como una isla orgullosa que no necesitaba para nada de la "cultura extranjera" ni de los viejos maestros de la cultura occidental. Fracciones de esa clase de escritores, falsos izquierdistas en lo político, además, llegaron a agruparse en un "Bloque de Obrero Intelectuales", levantándose contra las "Ideas de Moscú" desde su revista "Crisol", con lo cual le hacían el juego a la dictadura derechista del general Calles que necesitaba por entonces de un cierto ropaje intelectual. Elementos como los del Bloque de Obreros Intelectuales -los cito porque constituyeron el núcleo más típico-, consideraban a la Revolución Mexicana como un fenómeno exclusivo de México y, calculando como cualquier ropavejero, decían que nuestra Revolución, por haberse iniciado en 1910, mientras la rusa sólo comenzó en el 17, era más importante y que en consecuencia nada tenía que aprender nuestro pueblo de "ese movimiento extranjero".

Los escritores "revolucionarios" en general y como desentendiéndose de la existencia de Norteamérica, exaltan todo lo mexicano, acríticamente y tal vez juzgando que ésa es la forma de defensa que tiene el país en contra del "peligro yanqui". Para ellos México constituye todo y aún sus defectos resultan virtudes y motivo de emoción, como por ejemplo las fusilatas y la ley fuga. Pueden citarse al muy apreciable novelista Jorge Ferretis, que en su libro Cuando engorda el Quijote, aprovecha el relato de un viaje a los Estados Unidos, para defender, conmovido, ciertas costumbres feudales de nuestro país que contrastan con las modernas costumbres norteamericanas.

Los "revolucionarios" - de la literatura o de la política- no ignoran a lo que nos obliga, en todos los terrenos, en el de la Cultura, en el de la Economía, la presencia en nuestra historia presente y en la del porvenir, de los Estados Unidos, pero hacen como si lo ignorasen -se hacen "como que la Virgen les habla", para usar un giro de pueblo-, y prefieren entonces soslayar el problema, evitarlo, creando al mismo tiempo lo que en el futuro puede convertirse en un "fascismo cultural" de la peor especie. 


\section{Los hispanistas}

Más perniciosa aún que la actitud anterior, es la de los intelectuales "hispanistas". De paso hay que decir que no registran en sus filas ningún valor intelectual profundo, fuera de José Vasconcelos, uno de los talentos más arbitrarios y a la vez más seductores de México. Los "hispanistas" consideran que todo lo malo le llega al país de los Estados Unidos. Conforme a los "hispanistas" debemos defender a ultranza, todo lo hispano de nuestra cultura, e inclusive todo lo anti-indígena de la penetración española. Llegan a identificar de tal modo a la Iglesia Católica con la cultura de España y por ende, desde su punto de vista hispanófilo, con la nacionalidad mexicana, que preconizan un retorno a la Época Colonial, retorno que comprendería no sólo la cultura, sino también la organización política y económica que reinó bajo los virreyes. Los libros de Vasconcelos están destinados a propagar tal doctrina bajo el muy discutible ropaje de una confusa filosofía basada en la "raza cósmica”, que con el ingrediente español sería el vaso de una síntesis de la cultura universal. El resultado del pensamiento "hispanista" ha sido, por lo pronto, la formación de dos partidos reaccionarios y fascistas: la Unión Sinarquista y Acción Nacional.

Por otra parte, el "hispanismo" constituye una vieja actitud reaccionaria, con ejemplos numerosos en la historia de México. Si quisiéramos definirlo en lo que realmente es, podríamos decir que está constituido por una mezcla de sentimientos aristocráticos entre los que predomina cierto asco horrorizado frente a la psicología del pueblo. Estos sentimientos, que comprenden en el fondo otros de admiración hacia lo extranjero, "latino", han terminado siempre, a través de la historia de México, por convertirse en un servilismo auténtico hacia los poderes imperialistas, sean latinos o anglosajones, y de esta manera hemos tenido en el país como único fruto, un imperio de Maximiliano, llevado a México por los hispanistas de aquel tiempo, o una República de Texas, presidida por Lorenzo de Zavala, intelectual que en su hora también sintió el "hispanista" horror hacia los defectos del pueblo mexicano.

\section{Opinión del pueblo}

En México hay una minoría intelectual, compuesta en su mayor parte por jóvenes, que entiende con justeza el problema de la vecindad con los Estados Unidos y el problema de la serie de elementos que se derivan de esta vecindad. Probablemente -cuando yo lo ignoro- en los Estados Unidos también sean minoría los que comprendan, justamente el problema de la vecindad con México. Pero en todo caso ambas minorías no pueden trabajar la una sin la otra, no pueden luchar sin tenderse la mano, sin por su punto de vista en su propio país, con todas las fuerzas y con toda la intrepidez. Lo importante de esa minoría intelectual de México es que, si 
bien no todos los intelectuales piensan como ella, el pueblo, en cambio, sí tiene su mismo criterio. La minoría a que me refiero, que es una minoría de intelectuales revolucionarios sin comillas, entiende que ni México ni los Estados Unidos son países aislados y que ambos tienen, de igual a igual y con sus propios recursos, el deber de enfrentarse, junto con otros pueblos, a la tarea de crear un mundo nuevo para la humanidad. Esto plantea, como obra parcial dentro de la gran obra renovadora del mundo en la post-guerra, la de nuestras relaciones culturales de país a país, de pueblo a pueblo, de artistas a artistas, de pensadores a pensadores. En México imaginamos como posible la comunión de la cultura americana con la mexicana; imaginamos como posible la existencia de un cierto contrapunto armónico entre las dos sensibilidades. Ningún observador superficial hubiese creído por ejemplo, que Stalin, siendo un hombre que conoce tanto a su país, hablara algún día como lo hizo, de que el bolchevismo es la alianza "del ímpetu revolucionario ruso y del practicismo americano”. Sin embargo, la moderna Unión Soviética, con sus grandes fábricas, con su gran industria, con su extraordinario movimiento cultural y con su prodigiosa defensa, está demostrando que si a un ímpetu humano, que si a una emoción verdadera, que si a una fantasía, se les agrega ese "practicismo americano", los resultados son sorprendentes.

La parte de los intelectuales mexicanos que se coloca en el punto de vista más universal, acepta como un hecho futuro e inevitable, la alianza de nuestro espíritu nacional, de nuestro temperamento imaginativo, de nuestra profundidad estética, con el "practicismo norteamericano", entendido éste como síntesis del genio nacional de Norteamérica.

Pero ¿cuál es la clase de "practicismo norteamericano" que nosotros queremos en México? Desde luego que no es el "practicismo norteamericano" de los negociantes de la Staudart Oil; ni el rudo practicismo de los marinos yanquis en Nicaragua. Los mexicanos conscientes respetan y quieren a los Estados Unidos de hoy; a esos que con su "practicismo norteamericano" movilizan a los trabajadores para producir implementos contra los militaristas japoneses en China y el Pacífico, y contra los fascistas en Rusia. Pero los mexicanos conscientes aman mucho más a los Estados Unidos del futuro.

En esos Estados Unidos del futuro estamos empeñados, los mexicanos y los norteamericanos. Tal vez hoy tan sean sólo minorías de Estados Unidos y de México las que comprendan el problema de nuestro futuro común -más esencial que nuestro presente, pero por el que debemos luchar desde hoy mismo-, y para nosotros resulta prodigioso el imaginarnos lo que pueden llegar a ser los Estados Unidos cuando se convierten en un país sin discriminaciones raciales, sin plutocracia, sin pandillas imperialistas. Pero el que así sea es una tarea común de los intelectuales de México y Estados Unidos, siempre al lado de sus pueblos. 


\section{Nueva sensibilidad}

Creemos en la nueva sensibilidad norteamericana. En México han contribuido a descubrírnosla escritores tales como Teodoro Dreiser, Sherwood Anderson, William Faulkner, John Steinbeck, Richard Rigth (no cito a Ernest Heminway porque desconfío de los bestsellers sobre todo después de haberlos leído), y en otro orden Sinclair Lewis y John Dos Pasos, cuyas obras, saturadas de generosidad y de impulso, nos muestran el hecho espléndido de que nuestro sufrido, triste, ardiente pueblo mexicano, tiene hermanos, igualmente pobres, sufridos y llenos de esperanza en Norteamérica.

Ese país entrañable de Faulkner o Steinbeck, de Anderson o Rigth, es el que amamos. Además es el país con el que marcharemos lado a lado, mañana, cuando la aurora brille sobre el abatido cielo de la humanidad. 